\title{
A EMERGÊNCIA DO SUL-GLOBAL: DAS MARGENS DO MUNDO E DAS SUJEITAS DE DORES
}

\author{
João Luiz Moura de Sá*
}

\section{RESUMO}

Se a religião pode ser manipulada para dominação sobre outros e outras, as experiências religiosas gestadas no cotidiano podem criar ambientes de diversidade e compaixão. O presente artigo busca conhecer e dar visibilidade a mulheres que estão à margem das institucionalidades (ou não), mas na luta pelo reconhecimento da dignidade humana. Espera-se que as páginas que seguem possam provocar buscas por fissuras que se abrem no bloco das religiões hegemônicas ${ }^{1}$ que se vinculam à modernidade/colonialidade na América-Latina.

Palavras-chave: Colonialidade. Pós-colonialidade. Feminismo descoIonial. Religião e direitos humanos.

\section{LA EMERGENCIA DEL SUR-GLOBAL: DE LOS MARGENES DEL MUNDO Y DE LAS SUJETAS DE DOLORES}

\begin{abstract}
RESUMÉN
Si la religión puede ser manipulada para dominación sobre otros y otras, las experiencias religiosas gestadas en el cotidiano pueden crear ambientes de diversidad y compasión. El presente artículo busca conocer y dar visibilidad a mujeres que están al margen de las institucionalidades (o no), pero en la lucha por el reconocimiento de la dignidad humana. Se espera que las páginas que siguen puedan provocar búsquedas por fisuras que se abren en el bloque de las
\end{abstract}

* Mestrando em Ciências da Religião da Universidade Metodista de São Paulo (UMESP). Bacharel em Teologia pela Faculdade Unida de Vitória. Licenciado em Pedagogia pela Universidade Estadual Darcy Ribeiro.

1 Chamaremos aqui de religiões hegemônicas aquelas que têm maior acesso à mídia, e com isso, arrogam para si a "liderança ou representatividade" de determinado grupo. Instituições, denominações ou pessoas que marginalizam e subalternizam qualquer epistemologia que não venha do centro, ou não professam a mesma fé. 
religiones hegemónicas que se vincula a la modernidad / colonialidad en América Latina.

Palabras clave: Colonialidad. Pós-colonialidad. Feminismo descolonial. Religión y derechos humanos.

\title{
THE SOUTH-GLOBAL EMERGENCY: ON THE WORLD'S MARGINS AND THE SUBJECTS OF PAIN
}

\begin{abstract}
If religion can be manipulated for domination over others and others, religious experiences gestated in everyday life can create environments of diversity and compassion. This article seeks to know and give visibility to women who are on the margins of institutions (or not), but in the struggle for the recognition of human dignity. It is hoped that the pages that follow can provoke searches for fissures that open in the block of hegemonic religions that is linked to modernity/coloniality in Latin America.

Keywords: Coloniality. Pós-coloniality. Descolonial feminism. Religion and human rights.

E o risco que assumimos aqui é o do ato de falar com todas as implicações. Exatamente porque temos sido falados, infantilizados (infantis é aquele que não tem fala própria, é a criança que se fala na terceira pessoa, porque falada pelos adultos) que neste trabalho assumimos nossa própria fala. Ou seja, o lixo vai falar, e numa boa (Lélia GONZALEZ, 1984, p. 225).
\end{abstract}

\section{INTRODUÇÃO: DO COLONIALISMO À COLONIALIDADE}

Para compreender os estudos de gênero e as epistemologias que versam temas subalternos/subalternizados é imprescindível a compreensão dos estudos pós-coloniais. Desse modo, começaremos por apresentar alguns apontamentos acerca desses estudos. Este trabalho não tem como objetivo traçar uma linha genealógica exaustiva dos estudos pós-coloniais. As linhas que seguem têm um caráter ensaístico. Em seguida, exibiremos o pensamento crítico de Maria Lugones e a questão de gênero. Por fim, veremos dois exemplos de mulheres religiosas negras que estão abrindo fissuras no fazer e pensar espiritualidades insurgentes. Para isso, adotaremos como metodologia a pesquisa bibliográfica e de caso. 
A expressão "colonialidade" foi introduzida pelo sociólogo peruano Anibal Quijano, no final dos anos 1980 e no início dos anos 1990 (Walter MIGNOLO, 2017, p 1). Certo de que há um amplo debate acerca da melhor terminologia (epistemologias do Sul, pós-colonial, descolonial, transcolonial, estudos subalternos), o presente trabalho adotará a expressão "pós-colonial". Os estudos pós-coloniais são frutos de uma densa reflexão do grupo Modernidade/Colonialidade² que, segundo o professor Lauri Emílio Wirth, são reflexões contra:

À persistência atual de formas diversas de dominação oriundas dos centros coloniais, antigos e atuais, que se evidenciam na imposição de estruturas hierárquicas de classificação, de controle das relações de trabalho, de valoração dos processos de produção de conhecimento, com critérios de fundo étnico, raciais e de gênero, como relações práticas de poder, mas sempre naturalizadas no plano discursivo (Lauri WIRTH, 2013. p. 130).

Embora o colonialismo em sua fase formal tenha tido "fim", nas sociedades modernas há resquícios de colonialidades das mais variadas formas. Como coloca Walter Mignolo "pós-colonialidade nesse sentido não significa que a colonialidade terminou (do mesmo modo que pós-modernidade não se refere ao fim da modernidade), mas sim que se reorganiza em seus alicerces (a modernidade/colonialidade)" (Walter MIGNOLO, 2003, p. 134). Ao passo que, é preciso pensar a colonialidade para além de uma relação entre dois polos (metrópole $x$ colônia), mas como forma de organizar comportamentos, crenças, trabalhos, gêneros e, inclusive, as subjetividades. É preciso abrir suspeita em relação ao "fim da colonialidade". Considerar que ela, a colonialidade, permanece como base nas formas de pensar, nas preferências e comportamentos da sociedade moderna. Ou ainda, para usar uma expressão de Mignolo,

\footnotetext{
O projeto Modernidade/Colonialidade "nasceu com o novo século de um coletivo de pensamento crítico composto por acadêmicos e ativistas da América Latina. Nessa época, uma série de reuniões nos Estados Unidos e na América Latina, centradas em torno da teoria de Análise dos Sistemas-Mundo de Immanuel Wallerstein, formulada no meio do século XX, contaram com a pesquisa interdisciplinar de nomes como Walter Mignolo, Enrique Dussel, Aníbal Quijano, María Lugones, Edgardo Lander, Catherine Walsh, Arturo Escobar, Fernando Coronil e muitos mais" (CONTRAMARE.NET, 2015).
} 
é a representação de que o "pensamento colonial permanece nas obscurecências da modernidade" (Walter MIGNOLO, 2017, p. 2).

Essa distinção entre colonialismo e colonialidade é importante na medida em que permite explicar a continuidade das formas coloniais de dominação, muito embora os livros de histórias registrem o "fim" dos processos de colonialismo/extrativismo. Dessa maneira, a "nova colonialidade" pode ser percebida no que o sociólogo Boaventura de Sousa Santos chama de "localismo globalizado" (Boaventura de Sousa SANTOS, 2010, p. 439). Ou seja, determinado saber ou forma de vida criado e experimentado a partir da cultura local se estende para o globo a partir e por intermédio do seu capital financeiro. Quanto mais determinada realidade local - que se move pelo "espírito colonial" - possui capital, mais ela se torna influente no globo. Daí surge a hegemonia. Para Boaventura, tal fenômeno acontece a partir das diferenças culturais, raciais, sexuais, étnicas, religiosas, econômicas etc. Com efeito, pode-se concluir que as colonialidades estão intimamente ligadas ao poder financeiro de determinado grupo. Nesse propósito, não basta considerar o capital (e, por conseguinte, sua fase atual: neoliberalismo) uma ideologia da qual derivariam automaticamente políticas econômicas ou limitar sua análise aos aspectos negativos das políticas neoliberais, como a destruição programada das regulações e instituições sociais. A tese defendida por Pierre Dardot e Christian Laval, autores da obra "A nova razão do mundo: ensaio sobre a sociedade neoliberal", onde analisam com profundidade e exaustão aspectos da sociedade neoliberal da perspectiva do que Max Weber chamou de "razão configuradora do mundo", propõe que se compreenda não apenas as dimensões negativas das políticas neoliberais, como também - talvez principalmente - seus aspectos subjetivos, desejosos, fascinantes, aqueles que o tornam atraente e produtivo para a realização do controle total sobre territórios e populações.

Para criticar tal poder econômico e epistêmico de subalternizar, excluir e invisibilizar saberes e formas de vida que não venham do Norte global, Boaventura criou a ideia de uma "linha abissal". Para ele, há na modernidade ocidental uma espécie de linha abissal que divide dominantes (metrópole - Norte) de dominados (colônias - Sul). Boaventura 
usa os estudos pós-coloniais (ou epistemologias do Sul) para criticar a pretensa universalidade dos direitos humanos. Para Boaventura, os direitos humanos (no seu sentido mais amplo) foram criados para vigorar apenas nas metrópoles, porque no interior (sempre no centro) dessas categorias universais circulam lógicas de exclusão. Segundo Boaventura, "a grande maioria da população mundial não é sujeito de direitos humanos, é objeto de discursos de direitos humanos" (Boaventura de Sousa SANTOS, 2013, p. 42), haja vista os indicadores de mortalidade, dadas as injustiças sociais que marcam a população mundial, em especial a América Latina e o Norte da África.

Portanto, a partir das hermenêuticas de suspeição de Boaventura e tantos outros e outras, os estudos pós-coloniais abriram fendas importantíssimas nas bolhas hegemônicas eurocentradas e nortecentradas. Fendas que ajudaram a lançar luz sobre os saberes e formas de vida do lado de cá da linha, no Sul global. É importante notar que não apenas os saberes foram colonizados, mas também as formas de vida e as subjetividades. Ou, nas palavras de Suely Rolnik, há um "inconsciente colonial capitalístico" (Suely ROLNIK, 2018, p. 24). O cotidiano foi afetado. As linhas abissais foram sutilmente colocadas, de modo que o que fica do lado visível (Norte global) seja considerado/imposto como universal. Nesse sistema, existem os humanos: o homem branco, rico, heterossexual que é o detentor da razão e inteligência; e a mulher branca, rica, heterossexual que é reprodutora da dominação colonial heteronormativa da mentalidade masculina. E por fim, há os não humanos, aqueles que, segundo Judith Butler, não são considerados "passiveis de luto" (Judith BUTLER, 2017, p. 13). Nesse grupo estão os negros, as mulheres negras, os índios e as diversas formas de sexualidade que não se "enquadram" no binômio homem-mulher.

\section{COLONIALIDADES: AS NOVAS FORMAS DE UMA VELHA SACANAGEM}

Como vimos, os estudos pós-coloniais voltam o olhar para a expansão colonial iniciada com as grandes navegações e o "descobrimento das Américas" - e posteriormente com a implementação do neocolonialismo extrativista. Contudo, é importante dizer novamente que a perspectiva pós-colonial lança suspeitas à "extinção" do colonialismo/extrativismo 
nas Américas, com a construção de "nações independentes" no século XIX. Tais movimentos políticos não foram suficientes para a emancipação político-econômica e cultural dos países outrora colonizados. A fim de investigar com mais precisão os desdobramentos sociopolíticos desse processo, Anibal Quijano cunhou o conceito de colonialidade como algo que transcende as particularidades do colonialismo histórico e que não desaparece com a independência ou descolonização.

Para Anibal Quijano e o grupo Modernidade/Colonialidade, a colonialidade pode ser percebida a partir de três formas: colonialidade do poder; colonialidade do saber e colonialidade do ser. Vejamos:

A colonialidade do poder tem como objetivo dominar as instâncias de poder. Uma das formas de exercer tal domínio é a partir da exploração racial do trabalho, seus recursos e produtos. Raça (palavra importantíssima para os estudos pós-coloniais) foi uma categoria inventada para diferenciar e legitimar a exploração colonial. Segundo Quijano, "raça e identidade racial foram estabelecidas como instrumentos de classificação social básica da população"3 (Anibal QUIJANO, 2000, p. 2) A colonialidade do poder é um conceito para explicar o curioso "fenômeno" do garçom (ou de qualquer profissão que não goze de "destaque e prestígio") ser negro ou negra.

A colonialidade do saber é a colonialidade exercida sobre o conhecimento e as formas de conhecer. Dito de outra maneira, a colonialidade do saber tem íntima relação com as epistemologias e suas formas de reprodução do pensamento e das formas de pensar. A colonialidade do saber se apropria e oculta culturas e conhecimentos que não estão adequados às normatividades universais. $\mathrm{O}$ que Boaventura chamou de "epistemicídio" (Boaventura de Sousa SANTOS, 2010, p. 32), ou seja, formas de subalternizar e aniquilar pensamentos que não venham do Norte global. A lógica que opera no interior desses dispositivos é sempre a de que o pensamento europeu é superior às outras formas de conhecimento. Um exercício interessante: quantos filósofos negros ou negras você conhece? Quantos deles são estudados nas grandes escolas do mundo?

A colonialidade do ser tem intrínsecas ligações com a colonialidade do poder. A colonialidade do ser são formas de vida dos sujeitos

\footnotetext{
3 "En otros términos, raza e identidad racial fueron establecidas como instrumentos de clasificación social básica de la población."
} 
colonizados no interior da colonialidade do poder. A vida cotidiana é profundamente afetada por formas coloniais. Essa expressão colonial pode ser percebida, inclusive, nos movimentos de luta por garantia de direitos. Por exemplo, o feminismo branco, ao ignorar as subjetividades e as formas de vida peculiares das mulheres negras, acaba por reproduzir a colonialidade do ser.

Todavia, é preciso ir além das percepções (masculinas) acerca da modernidade/colonialidade, e investigar as questões de gênero implicadas no interior desses processos. Criticando as esquerdas e os movimentos "progressistas" na América Latina, o filósofo e transgênero Paul B. Preciado afirma que:

Para a esquerda, as questões feministas, da homossexualidade, da transexualidade, do uso de drogas, e também das relações racializadas de poder, ou dos conflitos pela soberania indígena, são questões secundárias com respeito à verdadeira, honrosa e viril luta de classes (Paul B. PRECIATO apud Suely ROLNIK, 2018, p. 19).

Nesse aspecto, é preciso conhecer, reconhecer e dar visibilidade ao trabalho seminal que Maria Lugones faz na intersecção entre raça, gênero e colonialidade. Lugones é filósofa feminista argentina nascida em família pobre. Seu pai era filho de um meeiro e sua mãe era filha de imigrantes catalães. Atualmente, é pesquisadora de filosofia no centro de semiótica da universidade de Binghamton, em Nova lorque, na área de estudos de mulheres, pesquisando especificamente ética, filosofia política, filosofia de raça e gênero, filosofia latino-americana, teorias de resistência, estudos subalternos, educação popular e política latina nos EUA. Participa da Sociedade para Mulheres na Filosofia de Midwest Division, da Associação americana de filosofia. É membro fundadora da Asociación Argentina de Mujeres en Filosofía e fundadora da Escola Popular Norteña, dedicada à criação e promoção do movimento de raça nos EUA. No LACAS (Programa de Estudos Latino-americanos e Caribenhos, na Universidade de Binghamton), o trabalho da autora foi de movimentar o programa para direcioná-lo para os estudos à América Latina e o Caribe, e em estudos sobre os latinos nos EUA. Os projetos buscam a compreensão das implicações do movimento diaspórico, e incluem pesquisas a respeito de educação popular na América Latina e grupos de estudos de pós-colonialidade. 
Em seus artigos incontornáveis: "Rumo a um feminismo descolonial" "Colonialidad y Género" "Heterossexualismo e o Sistema Colonial/ Moderno de Gênero", Lugones destaca o fato de que Anibal Quijano - apesar do reconhecido esforço ao falar de colonialidade - se baseia no binômio eurocêntrico homem-mulher (sempre no campo biológico). Para Lugones, o horizonte de reflexão de Quijano em relação às questões de gênero é heteronormativo. Desse modo, as reflexões de Quijano não correspondem à realidade colonial e o universo pluriversal das sexualidades subalternizadas. "Ao pensar a colonialidade do gênero, eu complexifico a compreensão do autor (Anibal Quijano) sobre o sistema de poder capitalista global, mas também critico sua própria compreensão do gênero visto só em termos de acesso sexual às mulheres" (Maria LUGONES, 2014, p. 939). Segundo Lugones, é preciso pensar as intersecções de gênero nas diversas formas de colonialidade. Há uma colonialidade de gênero (Maria LUGONES, 2014, p. 936), entendida tanto como resultado da construção no interior da modernidade de formas econômico-instrumentais de se pensar (ou não) as questões de gênero, quanto como expressão de processos concretos do binômio homem-mulher que sustentam a lógica prevalecente da acumulação capitalista e mantêm em funcionamento o sistema-mundo colonial moderno.

Com efeito, Lugones dilata o pensamento de Quijano ao reconhecer que - além das três categorias de colonialidades citadas - há que se pensar uma colonialidade de gênero. Segundo Lugones:

Eu investigo a intersecção de raça, classe, gênero e sexualidade para entender a preocupante indiferença que os homens demonstram em relação à violência que é sistematicamente infligida às mulheres de cor: mulheres não brancas; mulheres vítimas da colonialidade do poder e, inseparavelmente, da colonialidade do gênero; mulheres que criaram análises críticas do feminismo hegemônico precisamente por ignorar a interseccionalidade de raça/classe/sexualidade/gênero ${ }^{4}$ (Maria LUGONES, 2008, p. 75).

\footnotetext{
4 "Investigo la intersección de raza, clase, género y sexualidad para entender la preocupante indiferencia que los hombres muestran hacia las violencias que sistemáticamente se infringen sobre las mujeres de color:3 mujeres no blancas; mujeres víctimas de la colonialidad del poder e, inseparablemente, de la colonialidad del género; mujeres que han creado análisis críticos del feminismo hegemónico precisamente por el ignorar la interseccionalidad de raza/clase/ sexualidad/genero."
} 
Portanto, a colonialidade de gênero se manifesta nas ideias de teorias feministas hegemônicas, pois são ideias eurocentradas e universalizadas de emancipação da mulher, sem considerar as diferenças essenciais que existem entre as mulheres brancas, negras, latinas, índias, lésbicas e suas opressões. No limite, as categorias de gênero do pensamento pós-colonial - com profunda influência do pensamento colonial heteronormativo e masculinizado de gênero - não dão conta das subjetividades e diferenças das sexualidades que excedem o padrão eurocentrado e nortecentrado. Segundo a pesquisadora Letícia Otero Dias:

O sistema colonial/moderno de gênero também considera apenas os gêneros homem e mulher, e essas categorias de homem e mulher são extremamente limitadas. Dessa forma, as mulheres de cor e os transgêneros não são considerados nesse sistema. Maria Lugones propõe uma intersecção das categorias raça e gênero, para que, dessa forma, as mulheres de cor tenham visibilidade e tenham as características de suas próprias lutas reconhecidas. Essa intersecção deve acontecer de forma que se compreenda o entrelaçamento dos lados claro e escuro da colonialidade (Letícia DIAS, p. 8).

A modernidade se confunde com a colonialidade de gênero por meio da produção de políticas indenitárias de matriz essencialista, derivadas da identidade universal eurocêntrica: o homem branco, masculino, heterossexual e burguês como naturalmente superior e evoluído. Em relação a essa identidade universal se inventam as raças, gêneros, sexualidades e classes sociais subalternas, inferiores, escravizáveis e extorquíveis; ou, para amenizar, seres civilizados/civilizáveis. O super-eu europeu se impõe como identidade pura, essência e padrão universal. No entanto, a grande estratégia ideológica colonial seria apresentar tal política indenitária dominante por meio de conceitos universais abstratos como ciência, filosofia, cristianismo, marxismo, liberalismo e assim por diante.

Para perceber desobediências e insurreições no cotidiano colonizado, Anete Roese (2015) nos faz refletir sobre o campo religioso que se desenha nesse terceiro milênio, em especial a "autonomia feminina e o seu papel na sociedade”. Segundo Anete, há no Brasil diversas pessoas e/ou iniciativas religiosas apresentando fissuras nos blocos das religiões hegemônicas que, em aspectos decisivos, se vinculam à modernidade/ colonialidade de gênero na América-Latina e no Brasil. Para ela: 
As novas práticas religiosas, a vinculação das mulheres à religião ou as rupturas com as religiões protagonizadas por elas, as resistências, a subjetividade ativa delas como alternativas aos espaços tradicionais circunscritos pelo patriarcalismo religioso, bem como, a questão da autonomia e da responsabilidade das mulheres na construção de alternativas espirituais e religiosas na sociedade contemporânea merecem atenção (Anete ROESE, 2015, p. 1.534).

A seguir, veremos dois exemplos de espiritualidades insurgentes que têm lutado pela descolonização das questões de gênero na cidade do Rio de Janeiro.

\section{ESPIRITUALIDADE INSURGENTE: FORMAS DESOBEDIENTES DA VIDA RELIGIOSA}

Muito comum e apressadamente, a maioria das pessoas associa religião a um sistema de crenças rigidamente organizadas sobre uma realidade transcendente, sempre gerenciadas ou mediadas por instituições religiosas. Muitas das pessoas compreendem religião da perspectiva sistemática e institucional. Fala-se religião, pensam-se igrejas, livros sagrados, sacerdotes, templos e demais edificações, objetificações e institucionalizações da espiritualidade. E se imagina esse sistema de crenças de forma separada das outras dimensões da realidade social. Embora essa seja uma dimensão imprescindível para se pensar o fenômeno religioso, atualmente, ela não é suficiente nem a única possível. Religião não é - e não deveria ser - compreendida apenas da perspectiva institucional. O religioso não se define, nem se compacta ou se concentra unicamente pelos objetos sociais das religiões (Beatriz SOUZA; Luís MARTINO, 2004).

Dentro do universo de maneiras e possibilidades de se apreender o fenômeno religioso, destacaremos duas. Uma delas é olhar para as institucionalidades religiosas e perguntar sobre os modos de operação política, acerca das funcionalidades sociais daquele determinado sistema de crenças. Outro é, ir ao cotidiano das experiências humanas e tentar captar a religião da perspectiva de um fenômeno humano extasiante, excitante, afetivo e ético que dá sentido às experiências subjetivas das pessoas e das comunidades religiosas (Veena DAS, 2008). Pode-se analisar 
religião do ponto de vista da formalidade e da objetividade do sistema religioso, ou se pode tentar captá-la do ponto de vista do fenômeno subjetivo, no interior do cotidiano, como uma experiência de sentido que inspira e co-move a vida das pessoas e suas formas de viver no mundo, habitar e dar sentido ao mundo. Como disse Anete, "No século XXI, será nos espaços para além das religiões formais que poderemos averiguar o que é religião, sobretudo quando se trata de pesquisar o vínculo das mulheres com a religião" (Anete ROESE, 2015, p. 1.535).

A partir das metodologias da pesquisa de caso, a pesquisa toma como fonte o texto de Thamyra Thâmara na coluna \#AgoraÉQueSãoElas da Folha de S. Paulo, em junho de 2016, para analisar um caso de espiritualidade insurgente. Em um tempo histórico em que se questionava sobre a possibilidade de mulheres cristãs serem feministas, Thamyra empreende, a partir de uma experiência religiosa institucionalizada, um exemplo claro de descolonialidade de gênero e afirma categoricamente: "Sou cristã e feminista sim! E não podia ser diferente".

Thamyra Thâmara, jovem negra cristã, favelada e jornalista de 29 anos de idade, conta:

Cresci numa igreja cristã evangélica e foi nesse ambiente que aprendi muito sobre amor e respeito [...] Toda vez que paro para lembrar minha infância e adolescência na igreja vejo como foi caótica. Eu sempre fui a que ninguém queria pelo meu cabelo crespo, jeito expansivo e por ser filha de mãe solteira. Mulher na igreja é bem valorizada, mas só aquelas dentro do padrão "mulheres virtuosas", meninas tipo cor gelo, de cabelo lambido, discretas, silenciosas, de boa família, vestidas de forma decente e submissas. Como eu nunca fui nada disso, sempre fiquei meio que por ali. Infelizmente as igrejas (a religião cristã em si) têm sido uma das principais ferramentas de controle do corpo, em especial o feminino, e de reprodução do machismo. E machismo, meus irmãos, mata e é pecado. Mata porque naturaliza todo tipo de violência contra a mulher: física, psicológica e simbólica. E é pecado porque foge do alvo que é o amor. O amor é o alvo de todo cristão genuíno [...] E, nessa loucura toda, como você continua cristã? Na verdade, isso são coisas que vi produzidas pelo moralismo e pela doutrina das igrejas e que nada têm a ver com a essência do cristianismo baseado na figura de Cristo. Em seu amor perturbador. 
[...] as lideranças femininas também reproduzem esse jugo opressor ensinando desde cedo meninas mais jovens a serem as mulheres "virtuosas" que aceitarão tudo pelo bem da família. E ter uma família deve ser o sonho de toda mulher. Tudo isso é bastante complicado porque produz mulheres que levam consigo uma espiritualidade carregada de vergonha e de culpa por não conseguirem viver regras morais estabelecidas pela religião. Mulheres divorciadas, solteiras com filho, no segundo casamento, mulheres solteiras que exercem a sua sexualidade, solteiras com mais de 30 anos, mulheres casadas sem filhos. Essas mulheres, que são de fato a maioria de nós, são colocadas à margem no ambiente eclesiástico e passam a vida toda tentando se encaixar [...] Mas existe uma esperança! Se deixarmos de lado toda essa burocracia religiosa e olharmos o evangelho pelas lentes de Jesus de Nazaré, vamos perceber uma figura bastante revolucionária no contexto judaico da época. Uma época em que mulheres não significavam nada. Não tinham voz. Na Bíblia existem inúmeras histórias de Jesus andando com mulheres, compartilhando segredo com elas, aprendendo com mulheres, indo a suas casas, ouvindo e dando a elas ferramentas para potencializar suas vozes. O episódio que mais me encanta é quando Jesus ressuscita e a primeira pessoa para quem Ele resolve aparecer é uma mulher. O que é bastante louco porque naquela época o testemunho de uma mulher não valia nada. Ele não só aparece para uma mulher como a deixa encarregada de contar para o resto dos discípulos. Gosto de imaginar como ficou a cabeça daqueles homens durões (que chegaram a criticar Jesus por conversar com a mulher de Samaria). Eles devem ter pensado "por que Ele resolveu aparecer justo para uma mulher?" Todos provavelmente queriam ter sido o primeiro a saber, mas acredito que Jesus estava deixando um grande ensinamento: somos todos iguais e merecemos direitos, respeito e dignidade. É preciso que a gente entenda que evangélico não tem uma cara só. Não é sinônimo de Bolsonaros e Felicianos. A identidade evangélica está em disputa e tem uma galera comprometida e engajada, levantando a bandeira do acolhimento, do respeito à diversidade, do amor fraterno e da dignidade humana. Sou cristã e feminista sim! E não podia ser diferente, porque foi através desse amor revolucionário de Cristo que aprendi que não deve haver diferenças entre homens e mulheres. Somos todos iguais no elo de amor que é Ele (Gálatas 3.28) (Thamyra THÂMARA, 2016, s/n).

À época em que Thamyra deu essa entrevista para o Blog da Folha de S. Paulo, os mais variados recursos violentos foram acionados pelo 
fundamentalismo evangélico - principalmente os de corte neocalvinistas - em eventos no Brasil. Em uma roda de conversa na PUC Rio, no dia 25 de agosto de 2016, Thamyra relatou que, dias depois da publicação de seu texto na Folha de S. Paulo, foi falar em uma roda de conversa na cidade de Belo Horizonte e um grupo de jovens evangélicos foi até o local para hostilizá-la.

As palavras de Thamyra constituem um escândalo às espiritualidades fundamentadas nas violências de gênero e nos processos coloniais de sexualidade. Pastores ou leigos rapidamente, com olhares preconceituosos, lançaram mão da violência ética e da colonização moral como recurso de menosprezo da vida, do lugar, da memória e da fala de Thamyra que, naquele tempo, incorporava a crítica, a rebeldia e a divergência dessa normalidade violenta. Thamyra rompe com uma forma religiosa que "desde a idade média, no ocidente, esteve à frente do projeto de colonização de povos, raças e gêneros" (Anete ROESE, 2015, p. 1.537).

A espiritualidade insurgente e transgressora da colonialidade de gênero apresentada por Thamyra desafia as categorias metodológicas e empíricas e os modos de perceber e pesquisar a(s) religião(ões). Thamyra desloca a forma viciada de perceber a religião apenas como um conjunto de comportamentos e nos faz enxergar a potência que há nas formas desobedientes da vida religiosa. Como nos informa a pesquisadora Anete Roese:

Não está em jogo simplesmente criticar toda forma de religião e todos os elementos da religião. [...] as mulheres no mundo contemporâneo estão criando e recriando a sua vinculação, a sua relação de fé com o divino e o religioso de forma muito autônoma e criativa (Anete ROESE, 2015, p. 1.545).

Se por um lado a religião pode se manifestar como poder institucional, por outro, pode acontecer como potência de vida, força existencial e afetiva que inspira a vida e faz viver. Thamyra é protagonista de uma espiritualidade que está para além das institucionalidades denominacionais. Esse tipo de espiritualidade você pode encontrar, inclusive, fora das experiências tradicionalmente cridas e nomeadas de "religiosas". Haveria, assim, religião fora da religião institucionalizada. 
Outro exemplo investigado foi a entrevista de Fabíola Oliveira à Huffpost, em junho de 2018. A metodologia empregada para analisar tal entrevista também foi a pesquisa de caso. Diferente da discussão em que Thamyra estava inserida (a possibilidade de mulheres cristãs serem feministas), o contexto que cerca a entrevista de Fabíola são as questões raciais, o que ela faz questão de deixar claro: "Sou uma mulher preta cristã".

Fabíola Oliveira, jovem negra cristã, favelada, pedagoga de 34 anos de idade, conta:

Sou uma mulher preta cristã na resistência e na re-existência. Resistindo na prática de um evangelho que é inclusivo e que não comunga com a violência racista, homofóbica e machista. Foi num roncó, tocando adjá para Oyá, que eu soube que tinha um espírito ali que não era nenhum que eu conhecia. Não tinha nome, mas Deus é Deus, você consegue identificá-lo e eu senti. Só não faz sentido para o nosso pensamento cartesiano, para o crente que inventou que o espírito de Deus só se movimenta dentro de uma igreja evangélica. É piada reduzi-lo a um espaço. Não foi à toa que Cristo veio preto e favelado, e veio num ambiente em que a desqualificação e invisibilização era uma realidade, de onde nada de bom podia brotar. Era pra quebrar paradigma mesmo. Não tô falando de um Cristo ativista, estou falando de um Cristo que, sendo homem, era Deus, e veio para destruir, subverter e transgredir todo e qualquer entendimento que se tinha acerca de poder. Eu ser uma mulher negra, e que marca a favela na minha fala e na minha vida, é um absurdo. É o mesmo corpo passível de crucificação, porque é o corpo que ofende e subversivo em um espaço pasteurizado, em que as imperfeições, deficiências e necessidades são esquecidas. Isso é um contrassenso absurdo à ideia de Cristo, que disse que veio para quem estava precisando de ajuda. Dependendo do lugar, eu marco bastante a oralidade da minha comunidade, pra duvidarem mesmo. Se eu 'tô' falando "vagabundo, viado", se eu 'tô' gesticulando muito, se eu não 'tô' com a perna devidamente cruzada, vão duvidar da minha escolaridade e dos meus títulos, porque primeiro vem minha pele. A Marielle era transgressão, a afronta dentro daquele ambiente [da política institucional]. Quando o corpo dela tombou, caiu nossa esperança e possibilidade de fala. Mas ao mesmo tempo olhamos para o lado e percebemos que se deixássemos nossa voz se esvair com ela, acabou, gente voltaria para 
o tumbeiro de novo. Não acredito em proselitismo, e não estou aqui para educar branco, porque eu acredito que é o espírito de Deus que constrói ou destrói paradigmas. Mas eu não aguento mais carregar ódio no meu coração, o ódio já me adoeceu muito. Não quero mais odiar ninguém, eu quero me reconciliar com a vida, apesar de nunca às custas de silêncio. Mas se a pessoa branca quer se perceber engrenagem dessa violência e acabar com isso, vou caminhar com ela sim (Fabíola OLIVEIRA, 2018, s/n).

Fabíola é uma importante voz nas periferias do Rio de Janeiro. Ela é idealizadora do projeto Odarah. Uma iniciativa "de fomento e valorização da atuação de afroempreendedores no mercado da moda, arte, educação e cultura". Membro da Igreja Batista Betânia, em Sulacapi - periferia do Rio - Fabíola é a afirmação daquilo que Lugones disse "Não se resiste sozinha à colonialidade do gênero. Resiste-se a ela desde dentro, de uma forma de compreender o mundo e de viver nele que é compartilhada e que pode compreender os atos de alguém, permitindo assim o reconhecimento" (Maria LUGONES, 2014, p. 949).

A história de Fabíola é mais uma história de resistência ao espírito colonial que insiste e persiste em violentar corpos negros, mais especificamente corpos femininos. É importante perceber as fissuras provocadas por Fabíola. Segundo dados do Atlas da Violência 2018, do Instituto de Pesquisa Econômica Aplicada (Ipea), "a taxa de homicídio de mulheres negras no país é de 5,3 por 100 mil habitantes. O número é $73 \%$ superior ao registrado entre as mulheres não negras, cuja taxa de homicídios é de 3,1 por 100 mil habitantes". É importante observar que em dez anos a taxa de assassinatos de mulheres negras aumentou 15,4\%, enquanto entre as não negras caiu $8 \%$. A partir da experiência institucional, Fabíola ergue sua voz subalterna que "propõe uma ruptura com a produção feminista branca, e toda a produção eurocentrada e centrada na América do Norte, racialmente centrada e sexualmente centrada na classe branca e heterossexual" (Anete ROESE, 2015, p. 1.536).

Ao afirmar que "Cristo veio preto e favelado", Fabíola rompe com a ideia de um Jesus branco europeu. Ela traz para o centro da reflexão um problema que marca as nossas sociedades: o racismo. Esse problema, o racismo, é uma ferida que não se cura soprando, é preciso tocar 
nela profundamente. E esse exercício é doloroso. Fabíola e muitos outros e outras estão tocando nessa ferida a fim de resgatar a memória do povo preto, sofrido e marginalizado. Esse exercício constitui uma desobediência as teologias convencionais que seguem ignorando e marginalizando corpos femininos, pretos e LGBTs. Afirmar que Jesus é "favelado" é antes de tudo, um ato de resistência.

\section{CONSIDERAÇÕES FINAIS}

As epistemologias do Sul ou as críticas pós-coloniais desconstroem os consensos hegemônicos, que de uma maneira muito sofisticada justificaram e naturalizavam a destruição e a miséria dos colonizados, subjugados e oprimidos nas periferias do mundo. Questionar a "inquestionável universalidade" é perceber certa exclusão operante no interior dos saberes e das formas de vida do Norte global. A partir das categorias pós-coloniais se torna possível o reconhecimento de novos lócus de enunciação e de novos sujeitos e sujeitas e subjetividades desviantes e exteriores à normatividade colonial.

Dessa forma, pesquisas como as de Boaventura, Mignolo, Quijano, Lugones, Rolnik e tantos outros e outras, fornecem ferramentas para identificação de pessoas ou movimentos desobedientes e subversivos a partir das periferias e dos lugares considerados improváveis. A literatura bíblica, por exemplo, fornece um exemplo clássico sobre qual o lugar a periferia ocupa nos saberes hegemônicos: "Pode vir alguma coisa boa de Nazaré?", pergunta o desavisado. Como foi com o favelado de Nazaré - Jesus -, é possível o reconhecimento de novos lócus de enunciação, novas categorias epistemológicas podem ser descobertas e acionadas em projetos de caráter contra-hegemônicos. "Depois de três dias o encontraram no templo, sentado entre os mestres, ouvindo-os e fazendo-Ihes perguntas. Todos os que o ouviam ficavam maravilhados com o seu entendimento e com as suas respostas" (BÍBLIA SAGRADA, Lucas 2).

O presente trabalho buscou, a partir das discussões pós-coloniais, considerar espiritualidades insurgentes existentes no Brasil - em especial as de recorte feminino e negro. Quais são as inteligências produzidas pelas muitas mulheres religiosas brasileiras que podem nos ajudar a 
repensar questões de gênero no Brasil? As opções pós-coloniais se reposicionam e emergem a partir dessas exterioridades pluriversais: dos conhecimentos e práticas revolucionárias daqueles e daquelas "vencidas da história", subalternizadas, inferiorizadas, espoliadas e violentadas. A opção pós-colonial vive nos corpos indígenas das Américas, dos negros e negras, das memórias gravadas em corpos marginalizados por gerações. Vive na força criativa e revolucionária das vítimas da violência do desenvolvimentismo capitalista e da diferença colonial, aquelas que reinventam suas posturas no mundo alimentando-se das interculturalidades e pluriversalidades. A pós-colonialidade repousa do colo da diversidade. As mulheres negras são resistência à violência colonial. Elas são a nova política que vem. E que venha. Que venha Thamyra. Que venha Fabíola. Façamos essa história!

\section{REFERÊNCIAS}

BÍBLIA SAGRADA. Evangelho de Lucas - Capítulo 2. Nova Versão Internacional.

BUTLER, Judith. Quadros de guerra: quando a vida é passível de luto? Rio de Janeiro: Civilização Brasileira, 2017.

CONTRAMARE.NET. Modernidade Colonialidade. contramare.net. Disponível em: <http://www.contramare.net/site/pt/modernitycoloniality-decoloniality/>. Acesso: em 10 jul. 2018.

DARDOT, Pierre. A nova razão do mundo: ensaio sobre a sociedade neoliberal. São Paulo: Boitempo, 2016.

DAS, Veena. Sujetos del dolor, agentes de dignidade. Bogotá: Instituto Pensar, 2008.

DIAS, Letícia Otero. 0 feminismo decolonial de Maria Lugones. Dourados: UFGD-FADIR. Disponível em: <http://eventos.ufgd.edu.br/enepex/anais/arquivos/318.pdf>. Acesso em 10 de julho de 2018.

GONZALES, Lélia. Racismo e sexismo da cultura brasileira. Revista Ciências Sociais, 1984. Disponível em:

<https://edisciplinas.usp.br/pluginfile.php/247561/mod_resource/content/1/RACISMO\%20 E\%20SEXISMO\%20NA\%20CULTURA\%20BRASILEIRA.pdf.> Acesso em 14 set. 2018.

IPEA; FÓRUM BRASILEIRO DE SEGURANÇA PÚBLICA. Homicídio de mulheres negras. Fórum Brasileiro de Segurança Pública. Disponível em:

<http://www.forumseguranca.org.br/wp-content/uploads/2018/06/FBSP_atlas_violencia_2108_Infografico.pdf>. Acesso em: 10 ago. 2018. 
LUGONES, Maria. Rumo a um feminismo descolonial. Santa Catarina: Revista Estudos Feministas, 2014. Disponível em

$<$ https://periodicos.ufsc.br/index.php/ref/article/view/36755/28577>. Acesso em $10 \mathrm{de}$ jun. 2018.

. Colonialidad y Género. Bogotá: Tábula Rasa, 2008. Disponível em:

$<$ http://dev.revistatabularasa.org/numero-9/05lugones.pdf >. Acesso em 29 de jul. 2018. MIGNOLO, Walter. Histórias locais, projetos globais: colonialidade, saberes subalternos e pensamento liminar. Belo Horizonte: UFMG, 2003.

. Colonialidade: O lado mais escuro da modernidade. Rio de Janeiro, 2017. Dis-

ponível em:

<http://www.scielo.br/pdf/rbcsoc/v32n94/0102-6909-rbcsoc-3294022017.pdf >. Acesso em: 25 ago. 2018.

OLIVEIRA, Fabíola. A cristã que pratica uma religião mais inclusiva e menos violenta. Huffpost. Disponível em:

<https://www.huffpostbrasil.com/2018/06/21/fabiola-oliveira-a-evangelica-que-pratica-uma-religiao-mais-inclusiva-e-menos-violenta_a_23465021/?fbclid=IwAR2bivfDotSR7X gmYyoTt-YmCJ_jlorcRL5K_1D7Wqae5HelYT2_-7d39NE>. Acesso em: 22 jun. 2018.

QUIJANO, Anibal. Colonialidad del poder, eurocentrismo y América Latina. Disponível em <http://bibliotecavirtual.clacso.org.ar/ar/libros/lander/quijano.rtf >. Acesso em 15 de nov. 2018.

ROESE, Anete. Religião e feminismo descolonial: os protagonismos e os novos agenciamentos religiosos das mulheres no século XXI. Horizonte, v. 13, n. 39, p. 1.534-1.558, 2015. ROLNIK, Suely. Esferas da insurreição: notas para uma vida não cafetinada. São Paulo: $\mathrm{N}-1$ edições, 2018.

SANTOS, Boaventura de Sousa. Direitos humanos, democracia e desenvolvimento. São Paulo: Cortez, 2013.

. A gramática do tempo: para uma nova cultura política. São Paulo: Cortez, 2010. SOUZA, Beatriz e Luís MARTINO. Sociologia da religião e mudança social: católicos, protestantes e novos movimentos religiosos no Brasil. São Paulo: Paulus, 2004.

THÂMARA, Thamyra. Feminista e cristã pode? Disponível em:

<https://agoraequesaoelas.blogfolha.uol.com.br/2016/06/13/feminista-e-crista-pode/>. Acesso em: 15 jul. 2018.

WIRTH. Lauri Emílio. Religião e epistemologias pós-coloniais. In: PASSOS, João Décio, USARKI, Frank (orgs.). Compêndio de Ciência da Religião. São Paulo: Paulinas - Paulus, 2013.

Submetido em: 16-10-2018

Aceito em: 10-12-2018 